\title{
Characterization of the Kenyan Honey Bee (Apis mellifera) Gut Microbiota: A First Look at Tropical and Sub-Saharan African Bee Associated Microbiomes
}

\author{
Yosef Hamba Tola ${ }^{1,2}{ }^{\oplus}$, Jacqueline Wahura Waweru ${ }^{1}{ }^{1}$, Gregory D. D. Hurst ${ }^{3}{ }^{(0}$, \\ Bernard Slippers ${ }^{2}(D)$ and Juan C. Paredes $1, *$ (D) \\ 1 International Centre of Insect Physiology and Ecology (icipe), Nairobi 30772-00100, Kenya; \\ yosef@icipe.org (Y.H.T.); jackiemaingih@gmail.com (J.W.W.) \\ 2 Department of Biochemistry, Genetics and Microbiology, Forestry and Agricultural Biotechnology \\ Institute (FABI), University of Pretoria, Pretoria 0002, South Africa; bernard.slippers@fabi.up.ac.za \\ 3 Institute of Infection, Veterinary and Ecological Sciences, University of Liverpool, Liverpool L69 3BX, UK; \\ G.Hurst@liverpool.ac.uk \\ * Correspondence: jparedes@icipe.org
}

Received: 6 October 2020; Accepted: 29 October 2020; Published: 3 November 2020

\begin{abstract}
Gut microbiota plays important roles in many physiological processes of the host including digestion, protection, detoxification, and development of immune responses. The honey bee (Apis mellifera) has emerged as model for gut-microbiota host interaction studies due to its gut microbiota being highly conserved and having a simple composition. A key gap in this model is understanding how the microbiome differs regionally, including sampling from the tropics and in particular from Africa. The African region is important from the perspective of the native diversity of the bees, and differences in landscape and bee management. Here, we characterized the honey bee gut microbiota in sub-Saharan Africa using $16 \mathrm{~S}$ rRNA amplicon sequencing. We confirm the presence of the core gut microbiota members and highlight different compositions of these communities across regions. We found that bees from the coastal regions harbor a higher relative abundance and diversity on core members. Additionally, we showed that Gilliamella, Snodgrassella, and Frischella dominate in all locations, and that altitude and humidity affect Gilliamella abundance. In contrast, we found that Lactobacillus was less common compared temperate regions of the world. This study is a first comprehensive characterization of the gut microbiota of honey bees from sub-Saharan Africa and underscores the need to study microbiome diversity in other indigenous bee species and regions.
\end{abstract}

Keywords: Apis mellifera; African honey bee; Gilliamella; Frischella; gut microbiota; microbiome; symbiont

\section{Introduction}

Beekeeping has become an important tool to mitigate poverty, diversify income generation, and conserve biodiversity, in sub-Saharan Africa [1-4]. In Kenya, it provides critical pollination services, and contributes to food security and income generation for small-scale farmers in semi-urban and rural areas [5-8]. For instance, in Kakamega (densely populated farmland in Western Kenya), pollination services are estimated to generate about $40 \%$ of the annual crop market value [9]. Whilst there have been no reports of significant bee population decline in Kenya, common bee pathogens have been reported; thus, there is a need to assess the overall status of honey bee health in Africa [10,11].

Symbionts-beneficial associated microbes-have a profound effect on host physiology and fitness. In insects, these microbes play major roles in nutrition, protection against natural enemies, 
reproductive manipulation, communication, among others [12-19]. The honey bee, Apis mellifera, harbors a distinctive, simple, and specialized gut microbiota that play major roles in bee metabolism and health [20-25]. It is composed of nine bacterial phylotypes, five of which are found virtually in every honey bee worker [23,26-29]. Core members include the two Gram-negative bacteria Gilliamella apicola and Snodgrassella alvi that belong to the Gammaproteobacteria class and reside in the ileum, a zone between the midgut and the rectum [30,31]. G. apicola is located in the lumen and it is involved in sugar fermentation [22,25,31-33]. S. alvi, in contrast, is located at the vicinity of the gut epithelium and is a non-fermenting bacterium able to carry out aerobic oxidation of carboxylates, most likely, generated from G. apicola metabolism [22,30,31]. This complementary use of resources by different bacterial members, enables them to occupy the same niche, and it might be the result of a longstanding co-evolution [22,33-35].

Other highly abundant core gut microbiota include Lactobacillus, a vast genus that had its classification recently re-visited, and has been divided into 25 different genera [36]. In bees, members of the Firmicutes phylum group 4 and 5 have revealed to be the most widespread and abundant found in several species of corbiculate bees [27,29,32,37-40]. Some bee-isolated Lactobacillus strains have been shown to have antimicrobial properties against bee bacterial pathogens making them good candidates for use as probiotics [40-43]. Lactobacillus resides in the rectum together with Bifidobacterium asteroids, another core member that belongs to the Actinobacteria phylum $[37,38,44]$. Together, they have been shown to digest complex pollen aromatic compounds and ferment the derived sugars into organic acids $[22,33]$.

The other four core gut microbiota members are present in almost every worker bee and have been shown to induce additional important phenotypes. Frischella perrara is a Gammaproteobacteria closely related to G. apicola that resides in a restricted part of the gut called the pylorus, a short region between the midgut and the ileum [45]. F. perrara activates a melanization cascade in the pylorus that results in a dark band on the epithelium surface, called "scab phenotype" [45,46]; however, the potential role of this phenotype remains elusive. Members of the Alphaproteobacteria that include Acetobacter species (Commensalibacter sp., Apha 2.1), Bartonella apis (Alpha 1), and Bombella apis (Alpha 2.2) are also part of the core honey bee gut microbiota. These symbionts are also present in several species of corbiculate bees and are involved in sugar metabolism [27,47,48]. Finally, other prevalent members are Apibacter adventoris and Apibacter mensalis from Bacteroidetes phylum isolated from honey bee and bumble bee intestine [49-51]. Together with Lactobacillus Firm-5 and Gilliamella genus, Apibacter abundance has been reported to correlate with lower loads of a trypanosomatid bee parasite in bumble bees, highlighting the potential role of this group in bee health [52].

While A. mellifera harbors a conserved and simple gut microbiota, recent findings have uncovered a large hidden diversity at the strain level $[53,54]$. Moreover, it has also been reported that honey bee gut microbiota is shaped by seasons (i.e., diapause), landscape, and host genetic background [55-61]. Bee workers that survive over the winter harbor in their guts higher loads and less diverse bacteria affected by their diet during this period [59]. Surprisingly, whereas beekeeping has been widely promoted as a tool to mitigate poverty in tropical and subtropical regions of the world, no comprehensive studies of honey bee gut microbiota have been done in these regions, where there are no pronounced seasons, and pollen/nectar resources are present all year long [1,6].

Most of the gut microbiota studies are based on the fully domesticated European honey bee that has endure human artificially rearing and breeding for centuries. Additionally, common artificial feeding practices in western countries have been reported to be detrimental for bee gut microbiota $[62,63]$. In contrast to the western situation, sub-Sahara African bee keeping remains rudimentary and modern techniques and infrastructure are still under relatively low levels of adoption. Moreover, it hosts a highly significant and poorly studied A. mellifera genetic diversity (e.g., in Kenya, only, there are more than five subspecies, $[11,64])$. The current sub-Sahara African indigenous and traditional management methods, involving very little human intervention and frequent bee exchange between semi-managed and feral colonies (trapping feral swarms and high rates of colony absconding)—might be associated 
with significant and uncharacterized gut microbiota diversity selected for by different evolutionary pressures $[11,65]$.

Here we characterized the Apis mellifera scutellata gut microbiota from three different locations in Kenya. This is the first comprehensive study addressing the gut microbiota of honey bees from tropical sub-Saharan Africa and aims to establish the basis for future bee symbiont studies in this region. Profiling the diversity and effects of the local environment on the gut microbiota in Africa, constitutes an important resource to enhance bee health and climate change resilience; and thus sustainably promote beekeeping and bee services across the globe.

\section{Materials and Methods}

\subsection{Honey Bee Sample Collection and Preparation}

Honey bee (Apis mellifera scutellata) foragers were collected at the hive entrance in January 2018 from Western (Butali and Kalenda), Central (Githunguri, Kiambu, and Ruiru) and Coastal (Bahari, Matsangoni, Marenje, and Mwale) Kenya (Figure 1), from captive bred hives (i.e., feral bee swarms are collected by the beekeeper in Langstroth hives, absconding happens regularly). Ten forager worker bees per hive from 3 hives per site/apiary were collected and washed in $4 \%$ sodium hypochlorite, then $70 \%$ ethanol and finally $1 \times$ PBS for 2 min to eliminate any external microorganisms or contaminant DNA attached to the cuticle [66]. Entire guts were dissected aseptically using forceps and each gut placed in $2 \mathrm{~mL}$ microcentrifuge-tube containing $500 \mu \mathrm{L}$ PBS. Samples were stored at $-80^{\circ} \mathrm{C}$ before DNA extraction.

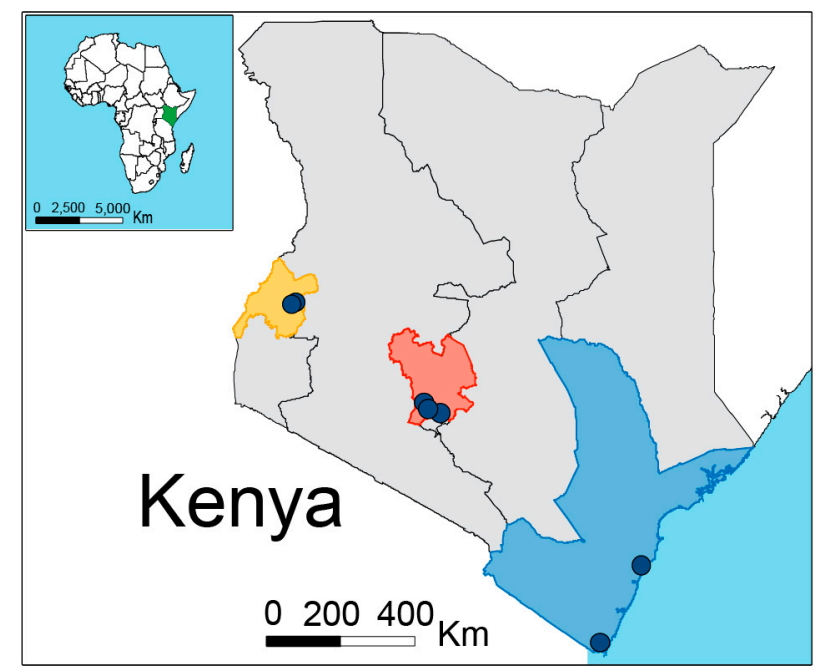

Figure 1. Sample collection map of Apis mellifera scutellata in Kenya. Western (yellow), Central (red) and Coastal (blue).

\subsection{DNA Extraction}

DNA extraction was done using the CTAB-Phenol-chloroform extraction method. Briefly, previously prepared intestinal homogenate tubes were placed in a $2 \mathrm{~mL}$ microcentrifuge-tube containing $750 \mu \mathrm{L}$ CTAB solution (20 g CTAB in 1L CTAB base: $100 \mathrm{~mL} 1 \mathrm{M}$ Tris-HCL pH 8, $280 \mathrm{~mL} 5 \mathrm{M} \mathrm{NaCl}$, $40 \mathrm{~mL} \mathrm{0.5} \mathrm{M} \mathrm{EDTA} \mathrm{pH} \mathrm{8,} \mathrm{complete} \mathrm{with} \mathrm{MilliQ} \mathrm{H}_{2} \mathrm{O}$ to a liter), $2 \mu \mathrm{L}$ b-Merc-ethanol and $100 \mu \mathrm{L}-200 \mu \mathrm{L}$ beads ( $3 \mathrm{~mm}$ diameter). Tissue homogenization was done at 30/s frequency for $3 \mathrm{~min}$ using the Tissue Lyser II QIAGEN and the homogenate was kept on ice. Then, $1 \mathrm{~mL}$ of phenol was added and mixed, and incubated at $64{ }^{\circ} \mathrm{C}$ for $6 \mathrm{~min}$, then, placed on ice for $5 \mathrm{~min}$ and the supernatant transferred into a $2 \mathrm{~mL}$ microcentrifuge-tube containing $400 \mu \mathrm{L}$ of chloroform and mixed by inverting several times, centrifuged at 13,000 rpm for $10 \mathrm{~min}$ at room temperature. The aqueous upper phase was transferred into a new microcentrifuge-tube. Then, $500 \mu \mathrm{L}$ Phenol-Chloroform-Isoamyl alcohol 25:24:1 was added, 
mixed, and centrifuged at 13,000 rpm for $3 \mathrm{~min}$ at room temperature. The aqueous upper phase was transferred into a new microcentrifuge-tube and $500 \mu \mathrm{L}$ of chloroform added again, then centrifuged at 13,000 rpm for $3 \mathrm{~min}$ at room temperature. The aqueous upper phase was transferred into a new microcentrifuge-tube and the DNA was precipitated using $900 \mu \mathrm{L}$ of $100 \%$ ethanol and incubated overnight at $-80^{\circ} \mathrm{C}$. Tubes were then kept on ice for $5 \mathrm{~min}$ to equilibrate temperature and centrifuged at 13,000 rpm for $30 \mathrm{~min}$ at $4{ }^{\circ} \mathrm{C}$. The DNA pellet was washed twice with $1 \mathrm{~mL}$ of $70 \%$ ethanol and then dried at room temperature for $10 \mathrm{~min}$. The DNA was re-suspended in $200 \mu \mathrm{L}$ MilliQ water.

\section{3. $16 \mathrm{~S}$ rRNA Gene Amplification and Sequencing}

Extracted DNA samples were quantified fluorometrically (Qubit, Thermo Fisher Scientific Inc., Waltham, MA, USA) and then diluted to $10 \mathrm{ng} / \mathrm{mL}$ for use as PCR template. Primers spanning the V4 region of bacterial 16S rRNA: 515f: 5'-GTGYCAGCMGCCGCGGTAA-3'; 806r: $3^{\prime}$-GGACTACNVGGGTWTCTAAT- $5^{\prime}$ were used $[67,68]$. Triplicate of $25 \mu \mathrm{L}$ reaction were amplified at an annealing temperature of $50^{\circ} \mathrm{C}$ using Platinum ${ }^{\mathrm{TM}}$ Taq DNA Polymerase High Fidelity enzyme for 25 cycles. Sequencing libraries were synthesized with the Kapa Hyper prep kit (Kapa Biosystems, Wilmington, MA, USA), according to the manufacturer's instructions. PentAdaptersTM (PentaBase, APS, Odense, Denmark) were used to barcode the library and were diluted according to Kapa's recommendation and the starting DNA concentration. After the final amplification step, libraries were then quantified using Qubit dsDNA BR Assay Kit (Thermo Fisher Sc., Waltham, USA, MA) and the fragment size was assessed on a Fragment Analyzer (Advanced Analytical Technologies, Inc. Ankeny, IA, USA). Finally, libraries were multiplexed and sequenced using paired end reads on a MiSeq instrument. All 16S rRNA gene amplification and sequencing was done at Center for Integrated Genomics, University of Lausanne, Switzerland (https:/wp.unil.ch/gtf/, accessed on 01/05/2018).

\section{4. $16 \mathrm{~S}$ rRNA Gut Community Analysis}

QIIME 2 (version 2019.10) was used for the 16S rRNA sequences analysis. Briefly, demultiplexing was done followed by visualizing the quality of the reads and trimming primers using Cutadapt (version 2.10). Low quality read trimming, denosing, chimera filtering, and merging the paired end reads was done using DADA2 [69]. Taxonomic classification was performed against SILVA132 database using a pre-trained Naive Bayes classifier [70,71]. Data was rarefied and Alpha diversity was determined using Evenness, Faith_pd, Shannon and chao1 index, and the statistical differences of gut microbiota diversity across the locations were tested using Kruskal-Wallis H test. Average diversity values were plotted for each sample at each even sampling depth and samples were grouped based on sample metadata. In addition, PERMANOVA was performed to compare microbial communities between locations [72]. To visualize the clustering of the microbial communities per locations principal coordinates (PCoA) was done using Bray-Curtis distances (multivariate community analysis). To establish the relative abundance of gut microbiota at the genus level across the locations, an ANOVA test using the least significant difference (LSD) test was performed using the R statistical software (v 4.0.2, Vienna, Austria). Pearson correlation test was additionally performed to identify the impact of altitude and humidity on the gut microbiota abundances across the locations.

\section{5. $q P C R$ Analysis}

Gilliamella absolute abundances were determined using quantitative PCR (qPCR) assays using specific primers targeting the 16S rRNA gene of Gilliamella and normalized to actin, the host housekeeping gene [22,66]. qPCR was carried out in on a Rotor-Gene $\mathrm{Q}^{\circledR}$ machine using $2 \mu \mathrm{L}$ of $5 \times$ HOT FIREPol ${ }^{\circledR}$ EvaGreen ${ }^{\circledR}$ HRM Mix from Solis Biodyne, $0.5 \mu \mathrm{L}$ of each primer, $5 \mu \mathrm{L}$ of the DNA template and $2 \mu \mathrm{L}$ of nuclease-free water. The amplification was conducted in the following steps: denaturation step at $95^{\circ} \mathrm{C}$ for $15 \mathrm{~min}$, followed by 40 cycles of denaturation at $95^{\circ} \mathrm{C}$ for $15 \mathrm{~s}$, annealing at $60^{\circ} \mathrm{C}$ for the $20 \mathrm{~s}$, and elongation at $72{ }^{\circ} \mathrm{C}$ for $20 \mathrm{~s}$, followed by a final elongation step for 
5 min at $72{ }^{\circ} \mathrm{C}$. Samples were run in duplicates. Variations of actin amplification, as a proxy of the gut size and extraction efficiency was minimal $(+/-0.5 \mathrm{Ct})$.

\section{Results}

\subsection{Bacterial Community Members Associated with Kenyan Apis Mellifera Gut}

We profiled the gut microbiota of 86 worker honey bee guts, from 9 apiaries from 3 different geographical zones in Kenya (Figure 1); Western Kenya ( 1700 m a.s.l., $0^{\circ} 29^{\prime} 16.7^{\prime \prime} \mathrm{N} 34^{\circ} 50^{\prime} 12.2^{\prime \prime} \mathrm{E}$ and $0^{\circ} 27^{\prime} 23.4^{\prime \prime} \mathrm{N} 34^{\circ} 46^{\prime} 34.8^{\prime \prime} \mathrm{E}$ ) characterized by fertile agricultural lands with small farm size in the proximity of a conserved native rainforest; Central Kenya ( $1900 \mathrm{~m}$ a.s.l., $1^{\circ} 08^{\prime} 27.7^{\prime \prime} \mathrm{S} 36^{\circ} 57^{\prime} 33.5^{\prime \prime} \mathrm{E}$, $0^{\circ} 59^{\prime} 49.4^{\prime \prime} \mathrm{S} 36^{\circ} 43^{\prime} 11.6^{\prime \prime} \mathrm{E}$ and $1^{\circ} 04^{\prime} 36.2^{\prime \prime} \mathrm{S} 36^{\circ} 47^{\prime} 22.9^{\prime \prime} \mathrm{E}$ characterized by high lands, intensive small farm agriculture and semi-urban lands; and Coastal Kenya ( 0 m a.s.l., north: $3^{\circ} 23^{\prime} 18.3^{\prime \prime} \mathrm{S} 39^{\circ} 55^{\prime} 30.8^{\prime \prime}$ $\mathrm{E}$ and $3^{\circ} 53^{\prime} 45.5^{\prime \prime} \mathrm{S} 39^{\circ} 36^{\prime} 28.0^{\prime \prime} \mathrm{E}$, and south: $4^{\circ} 31^{\prime} 42.4^{\prime \prime} \mathrm{S} 39^{\circ} 09^{\prime} 37.4^{\prime \prime} \mathrm{E}$ and $4^{\circ} 33^{\prime} 20.4^{\prime \prime} \mathrm{S} 39^{\circ} 07^{\prime} 42.7^{\prime \prime} \mathrm{E}$ ) characterized by small agricultural farms. We analyzed 2,117,668 reads (average per sample 24,698, min 6357, and max 76,320) from the V4 region of $16 \mathrm{~S}$ rRNA and we identified 4748 amplicon sequence variants (ASVs) (Table S1). We found the core honey bee gut microbiota members: genus Gilliamella, Snodgrassella, Lactobacillus (Firm-4 and Firm-5), Bifidobacterium, Frischella, Commensalibacter, Bombella, Apibacter, and Bartonella (Figure 2, [29,38,73]).

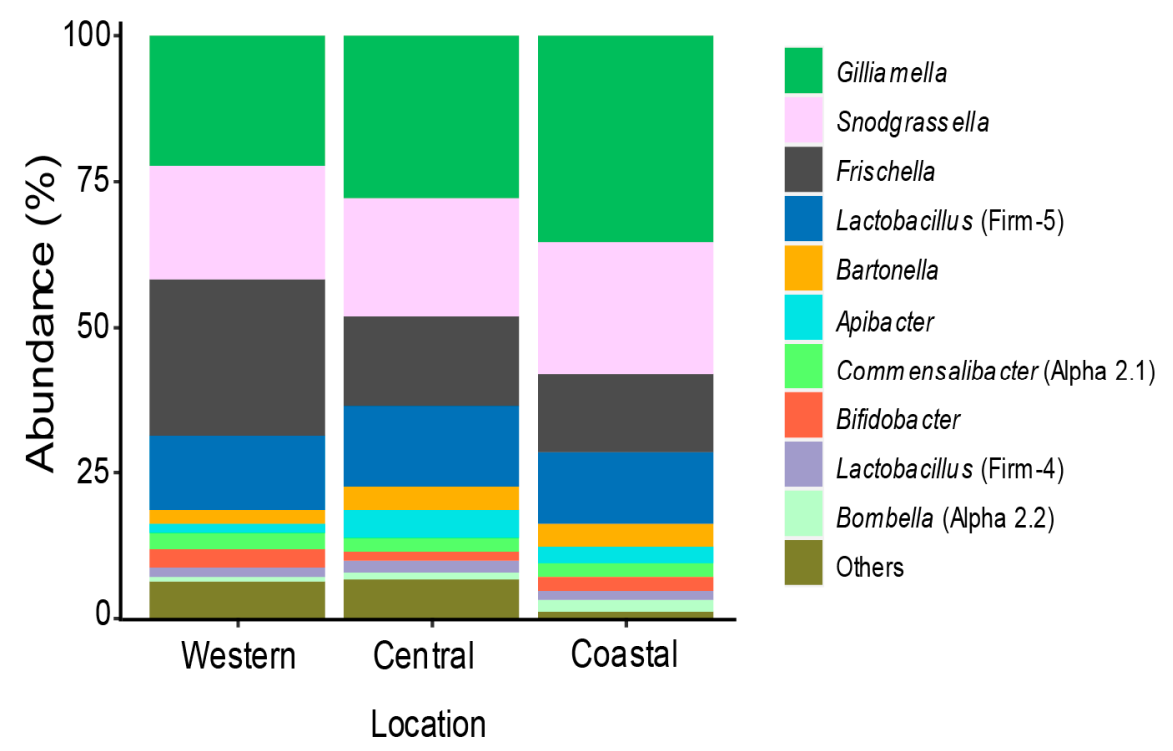

Figure 2. Bacterial genera associated with Apis mellifera scutellata gut in three different agro-ecological zones in Kenya.

As reported in other continents, Gilliamella and Snodgrassella were the dominant members of the core gut bacteria in Kenya (30.4\% and $21.4 \%$ of reads, respectively) and present in all worker bee sampled $[25,55,59,74]$. Interestingly, we found Frischella to be the third dominant genus with an average of $16.9 \%$ reads among locations in Kenya with a high prevalence, $94 \%$ (Figure 2). Additionally, we observed the scab phenotype induced by this bacterium in our samples (up to $34 \%$, data not shown, [45,46]). The relative abundance of Lactobacillus Firm-5 and Firm- 4 where lower than expected when compared to other studies at only $12.9 \%$ and $1.7 \%$, respectively, and a prevalence of $100 \%$ and $85 \%$, respectively $[27,38,73,75,76]$. Furthermore, we found Commensalibacter sp. (Alpha 2.1) at a prevalence of $81 \%$ with an abundance of $2.4 \%$. We also found Apibacter mensalis with $3 \%$ of the reads on average, and a prevalence of $62 \%$, which contrasts with other studies that described higher relative abundance in Apis dorsata and Apis cerrana, but not in A. mellifera [27,49-51].

Apart from the core gut microbiota members, our analysis uncovered minor taxa group that we grouped as "Others" in Figure 2 and Table S1 that collectively represent less than 10\% of all reads. 
The relative abundance of each taxa was very low-the highest was Pseudomonas with $2.3 \%$, the second highest Acidovorax with 2.1\%, then Spiroplasma with 2\%, and finally Gluconobacter with $1.7 \%$. The four taxa together represent around $8 \%$ of the reads but their presence was very scattered and uneven among samples from the same hive and/or from the same apiary (see Tables S1 and S2 with the list of 10 most prevalent taxa on the "Others" category).

Together, the specific relative abundances and prevalence of the core members in our samples highlight a potential specialized local community composition in tropical sub-Saharan Africa.

\subsection{Variation of Honey Bee Gut Microbiota Across the Locations}

Honey bee gut microbiota is relatively constant across populations and geographies worldwide [29, $38,49,55,73,76]$. However, some studies have revealed the influence of landscape exposure, forage type, and agrochemicals on honey bee gut microbial communities [58,61]. We analyzed the overall diversity of worker honey bee gut bacteria in the three study sites. We rarefied our data to 10,000 reads (Figure S1) and found that bacterial diversity, as measured by ASVs species richness and evenness, does not significantly differ among the sites (Figure 3). Whilst evenness of the samples is very similar (Evenness: $H=1.90, p=0.39$ ), richness is more marked in the coastal and western samples when phylogenetic distances are taken into account (Shannon: $H=0.81, p=0.67$ vs. Faith-PD: $H=5.49$, $p=0.06$, Figure 3). This finding is further supported by the higher numbers of ASVs of core members present in the coastal samples compared to the other two locations (Figure S2).

A
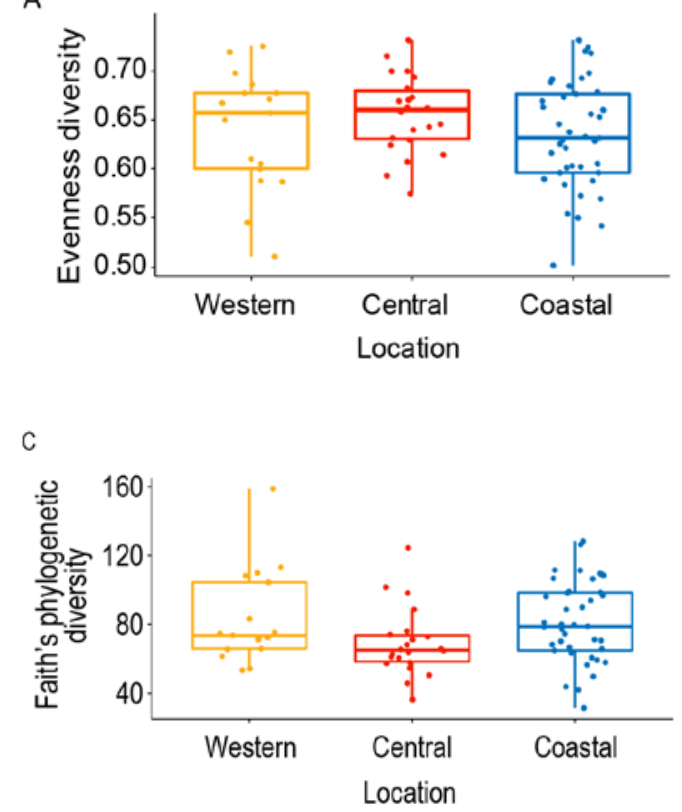

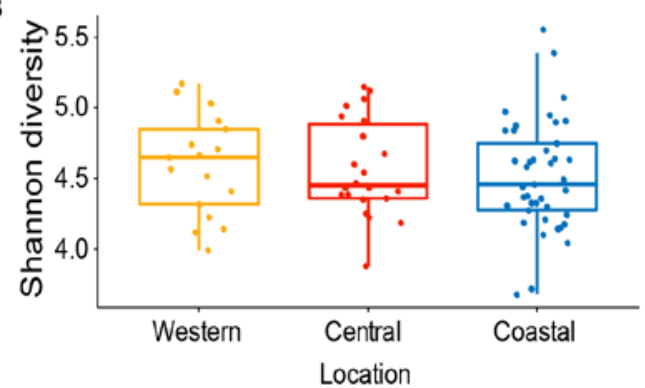

D

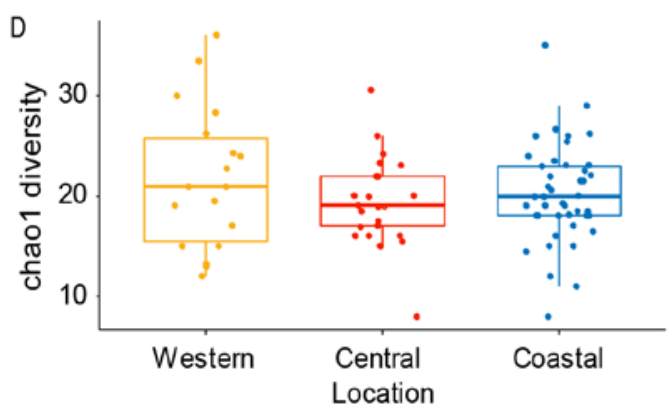

Figure 3. Alpha diversity analysis showed no bacterial community variation among locations. (A) Evenness diversity, $(p=0.39, H=1.90)$, (B) Shannon diversity ( $p$-value $=0.67, H$ value $=0.81$ ), (C) Faith's phylogenetic diversity, $(p=0.06, H=5.49)$, (D) chao1 diversity ( $p$-value $=0.54$, $H$ value $=1.2307)$ from Kruskal-Wallis $H$ test.

Additionally, PERMANOVA (beta diversity) results revealed that there was no significant difference in distribution of bacterial communities between the locations, $\left(R^{2}=0.03074, p=0.198\right.$, Table S3) and principal coordinate analysis also supported this conclusion (Figure 4). 


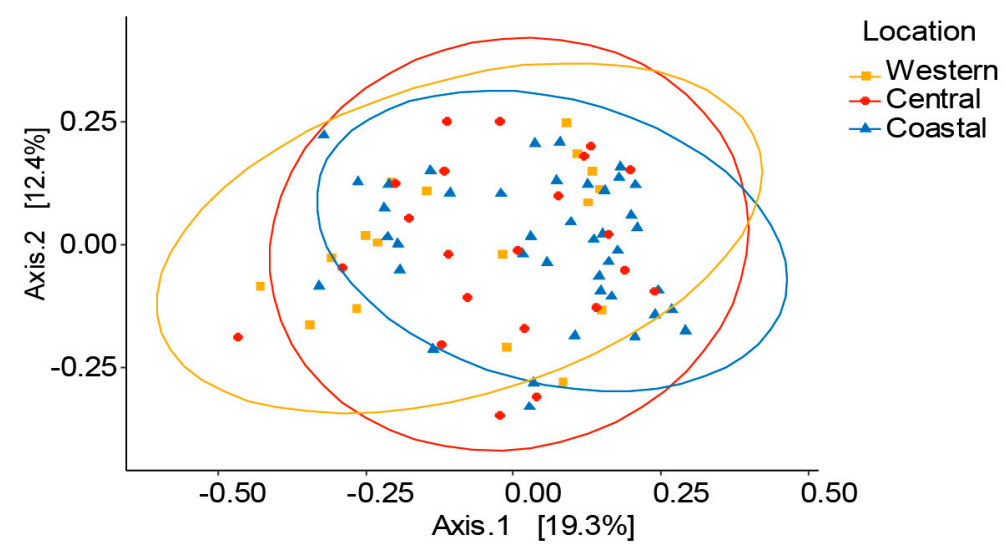

Figure 4. Beta diversity analysis showed no bacterial community variation among locations. Beta diversity (Principal coordinates) analysis based on Bray-Curtis distances (Multivariate community analysis). Different shades of each color indicate the distribution of the microbiota in respective to the locations.

The overall analysis showed there was no major variation of $A$. $m$. scutellata gut microbiota across different locations highlighting how conserved in honey bee gut microbiota even in very different ecosystems (high lands vs. coastal area). Nonetheless, we found that the coastal region presents higher relative abundance and diversity of core members compared to western and central lands. Additionally, we uncover less environmental/opportunistic bacteria in the bee gut (see Figure 2 "Others" and Tables S1 and S2), indicating that the coastal ecosystem is a more suitable environment for beneficial bacteria growth, and they might outcompete environmental/opportunistic bacteria.

\subsection{Gilliamela Abundance is Affected by the Local Environment}

We investigated variations in the gut microbiota at the genus level across all of our sampling locations (Table S3). Gilliamella, the most dominant core member in our study, showed significance differences across the locations and was significantly dominant in the coast (relative abundance measured as number of reads/total reads, $p=0.05$, Table S4). We confirm this finding by performing an absolute quantification of Gilliamella using qPCR in all samples across locations (Figure 5A, $p=0.000027$ ). Snodgrassella, Lactobacillus (Firm-4 and -5), Bifidobacterium, Bartonella, and Bombella had also higher number of reads in the coast samples although their relative abundance was not statistically significant (Figure S2 and Table S4). For a better understanding of the impact of environmental factors on gut microbiota abundances, we investigate potential correlations between Gilliamella-altitude and humidity. We found that Gilliamella abundance was negatively correlated with altitude $(R=-0.87$, $p=0.0024$, Figure 5B) and positively correlated with humidity ( $R=0.86, p=0.0032$, Figure $5 C)$. 

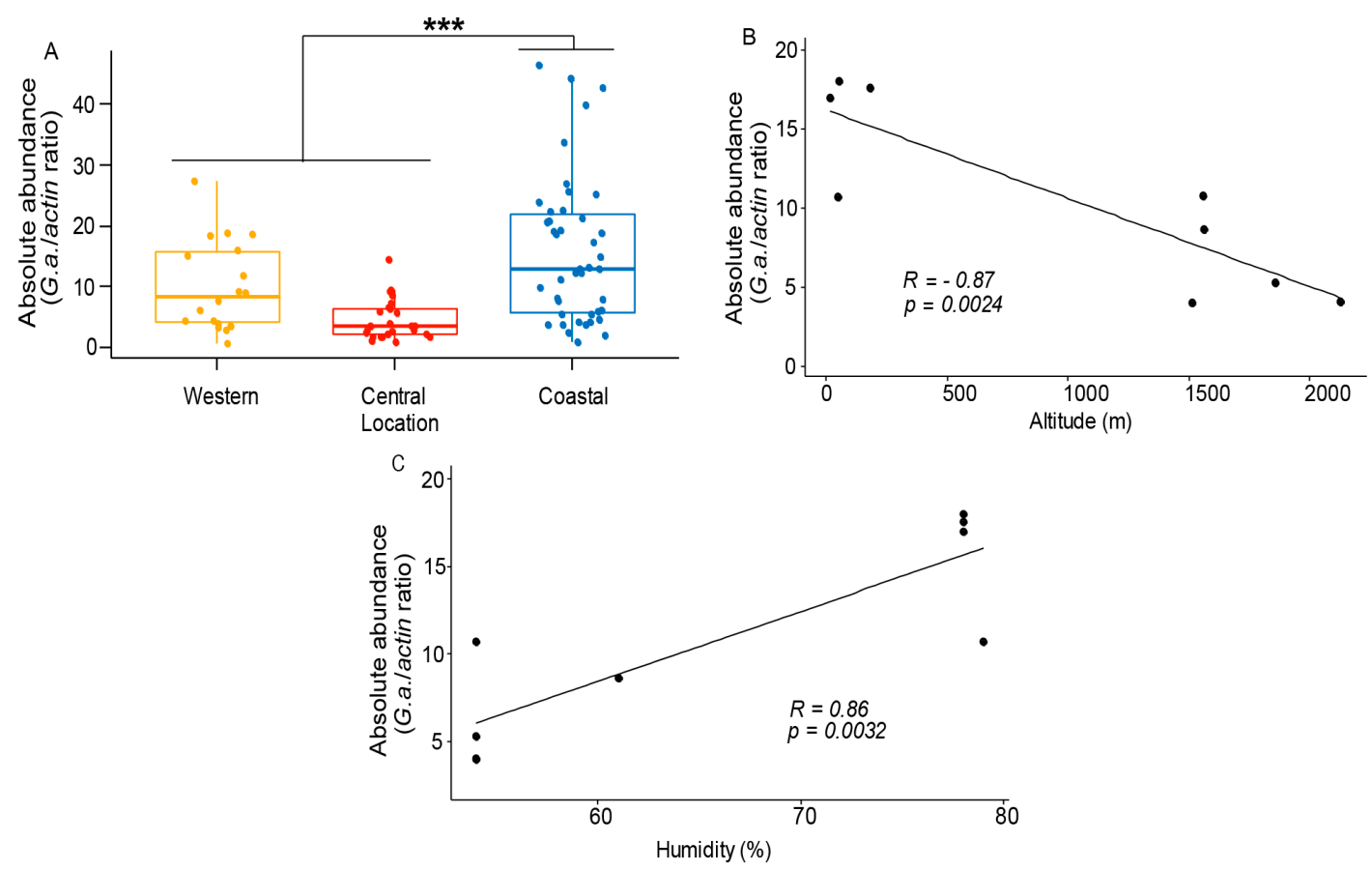

Figure 5. Gilliamella abundance varies across locations and significant correlates with the altitude and humidity. (A) Gilliamella absolute abundance across locations based on GPCR (*** $p=0.000027)$, (B) and (C) Correlation of Gilliamella abundance with the altitude and humidity per apiary, correlation coefficient $(\mathrm{R})$ and $p$ values were obtained using Pearson parametric correlation test.

\section{Discussion}

We carried out an initial characterization of the A. m. scutellata gut microbiota in tropical regions and investigated the impact of different geographical zones on the diversity of bacterial communities and the relative abundance of bacterial members. Our results showed significant differences in relative abundance of core members in the tropics, compared to studies in other latitudes, and uncovered the importance of the local environment for bacterial community composition. Since the gut microbiota has a profound effect in bee health, this study lays a critical foundation for a better understanding of African honey bee fitness and resilience against local environmental stresses and therefore to secure the role of beekeeping as a sustainable tool to reduce poverty in sub-Saharan Africa.

Our results show the presence and high relative abundance of the core honey bee gut microbiota. This suggests that the core bacterial communities are mostly constant across latitudes. Nonetheless, we found that the Kenyan coastal region harbors a higher diversity and a higher relative abundance of core members than other sites in Kenya. In addition, we show that Gilliamella is significantly more abundant in the coastal region and that this abundance correlates (inversely) with altitude and humidity. Interestingly, our results show that the Frischella is prevalent and dominant in Kenya, while the genus Lactobacillus was proportionally less abundant than expected when compared to studies done in other latitudes $[35,38,59,73]$.

We found that most of the core gut microbiota members are proportionally more abundant in the coastal region where they have also a greater number of amplicon sequence variants (ASVs). There is increasing evidence that temperature plays an important role in gut microbiota composition in invertebrates [77]. We noted that coastal apiaries were surrounded by small scale agriculture that was similar to central and western apiaries; the weather, in particular temperature and humidity are constantly higher throughout the year. We did not find any effect of temperature on the gut microbiota abundance (data not shown); nonetheless, a more exhaustive sampling across altitudes (which largely correspond to different temperatures) is needed to clearly rule out the effect on temperature in the overall bacterial community. We speculate that the coastal abiotic conditions might be more suitable 
for the bee core gut microbiota members, although we cannot exclude the effect of specific endemic flora that might have an impact on the bacterial community through pollen and nectar metabolism and nutrition. Unfortunately, the $16 \mathrm{~S}$ amplicon sequencing resolution did not allow us to characterize this diversity at the genomic and metabolic levels; metagenomics analysis (e.g., shotgun sequencing) will be needed for a better understanding of the structure of these communities [53]. Our study highlights the importance of the ecological niche for bee gut bacterial composition and give the first general overview of bacterial residents of the sub-Saharan bee gut.

Gilliamella are the most dominant bacteria in Kenyan A. m. scutellata gut microbiota, which is analogous to what has been described in recent studies elsewhere [22,33,55]. Gilliamella is highly abundant at the coast where it shows the highest diversity of ASVs. The abundance of Gilliamella is negatively correlated with altitude and positively correlated with the humidity. It has been reported that seasonal variation influences Gilliamella abundance in Europe and North America $[55,59,78]$. Our study is the first to report such fluctuations among locations in tropics. It is noteworthy that Gilliamella abundance increases in honey bees that are chronically exposed to the insecticides Fipronil and Thiamethoxam, as well as to the herbicide glyphosate [79,80]. These chemicals are registered and in use in Kenya and likely also in the farms surrounding sampled apiaries. Further studies should address the effect of these chemicals on Gilliamella in Kenya and asses a potential role in chemical detoxification and/or chemical selection of this bacterium in the gut of the bees located in the proximity of the use of these chemicals in agriculture, which could enlighten possible links between Gilliamella abundance and bee health.

We found that Frischella has the third highest relative abundance and prevalence in Kenyan A. m. scutellata gut microbiota, in contrast to studies in other continents where its presence is highly scattered and low in abundance [27,58,59]. Additionally, we also found the "scab" phenotype caused by F. perrara inducing the activation of an immune response in the pylorus region of the gut $[45,46]$. A role for F. perrara in pathogen protection through immune priming induced by this bacterium against a local pathogen could be plausible; nonetheless, we did not find any correlation between F. perrara abundance/presence and a potential bacterial pathogen abundance/presence (e.g., Serratia or Pseudomonas (data not sown), [23]). Future studies measuring infection of other pathogens in the same samples, such as fungi or trypanosomes, can help to elucidate any protective host phenotype of F. perrara in Kenya. F. perrara abundance has been also positively correlated with aged pollen consumption, impaired development, and increase mortality in honey bees in Arizona, USA [81]. Nonetheless, our samples were collected in highly productive hives and its prevalence was high among samples (94\%), which does not suggest detrimental effects of Frischella in Kenya. Together, the significant abundance and the induced-phenotype indicate that Frischella is very likely to play an important role in Kenyan bee physiology.

The relative abundances of Lactobacillus (Firm-4 and -5) are quite low in our study compared to samples from the Europe, Australia, Asia, and USA [27,38,73,75,76]. Studies have shown significant reduction of Lactobacillus in response to fungicides and insecticides used in Kenya [80,82]. Our data does not allow us to determine if the relative low abundance of Lactobacillus Firm- 4 and -5 in Kenya is due to complementary digestive roles performed by other bacteria (e.g., Bifidobacterium and Bacteroidetes), bee genetic background, absence of seasons, or chemical exposure.

Interestingly, Apibacter was prevalent in our samples. Apibacter have been described mostly in bumble bees and Asian honey bee species (A. cerrana and A. dorsata), but rarely in A. mellifera $[27,49,51]$. It is likely that Apibacter sp. may participate in simple sugar digestion and host gut parasite protection in A. m. scutellata [52]. Addressing its correlation with bee pathogen presence in the hive, and survival experiment with mono-inoculated lines with Apibacter sp., could bring further insight into their role in sub-Saharan African bees.

In this study, we provide an initial characterization of the gut microbiota of $A$. m. scutellata from sub-Saharan Africa. We showed that core members of the bee gut microbiota are highly conserved in the tropics compared to other latitudes, and we report specific and interesting diversities that are 
affected by the local environment. Our results highlight the importance of future studies of honey bee gut microbiota in Africa and in the tropics where native bee species are present, which will contribute to the understanding of the role of single members and the whole community in bee health. Additionally, traditional beekeeping practices that involve very little human intervention, which are still the most common practices in the continent, might have led to different selective pressures on the bee gut microbiota community. A better understanding of this indigenous bacterial biodiversity will not only continue to position the honey bee as an important model for gut microbiota research, but might also help address global challenges, such as bee decline and climate change resilient agriculture through enhancement of pollination services.

Supplementary Materials: The following are available online at http://www.mdpi.com/2076-2607/8/11/1721/s1, Figure S1: Rarefaction curve (OTUs per reads/sample). Figure S2: Amplicon sequence variant (ASV) relative abundance of the main bacteria core members. Table S1: 16S rRNA sequencing data analysis (Excel file). Table S2: Most abundant environmental bacterial abundance and prevalence. Table S3: PERMANOVA analysis showed no bacterial community variation among locations. Table S4: Pairwise comparisons of bacterial relative abundance showed significant variation of Gilliamella among locations.

Author Contributions: Conceptualization, J.C.P., G.D.D.H., and B.S.; investigation, Y.H.T.; data curation, Y.H.T. and J.W.W.; formal analysis, Y.H.T., J.W.W., and J.C.P.; funding acquisition, J.C.P.; methodology, Y.H.T. and J.C.P.; visualization, Y.H.T., J.W.W., and J.C.P.; writing-original draft preparation, Y.H.T. and J.C.P.; writing-review and editing, J.C.P., J.W.W., G.D.D.H., and B.S.; project administration: J.C.P.; All authors have read and agreed to the published version of the manuscript.

Funding: This research was funded by the Newton-Utafiti grant from the British Council (grant 275898413), the Swiss National Science Foundation Postdoc Mobility (grants P300PA_174329 and P2ELP3_165168) and German Academic Exchange Service (DAAD), grant 91671945, and by icipe core donors (see Acknowledgments).

Acknowledgments: The authors gratefully acknowledge the financial support for this research by the following organizations and agencies: The Newton-Utafiti grant from the British Council (reference 275898413) and German Academic Exchange Service (DAAD) In-Region Postgraduate Scholarship for Y.H.T (reference 91671945); icipe core funding provided by UK Aid from the UK Government, Swedish International Development Cooperation Agency (Sida), Swiss Agency for Development and Cooperation (SDC), Federal Democratic Republic of Ethiopia, and the Government of Kenya. The views expressed herein do not necessarily reflect the official opinion of the donors. We are additionally grateful to Jeremy Herren for manuscript review and to the Kenyan beekeepers in Nairobi, Kakamega, Kilifi and Kwale county, to our field experts James N'ganga and Joseph Kilonzo, and icipe bee health gut microbiota laboratory team.

Conflicts of Interest: The authors declare no conflict of interest. The funders had no role in the design of the study; in the collection, analyses, or interpretation of data; in the writing of the manuscript, or in the decision to publish the results.

\section{References}

1. Carroll, T.; Kinsella, J. Livelihood improvement and smallholder beekeeping in Kenya: The unrealised potential. Dev. Pract. 2013, 23, 332-345. [CrossRef]

2. Gidey, Y. Assessment of beekeeping practices in Asgede Tsimbla district, Northern Ethiopia: Absconding, bee forage and bee pests. Afr. J. Agric. Res. 2012, 7, 1-5. [CrossRef]

3. Kuboja, N.M.; Isinika, A.C.; Kilima, F.T.M. Determinants of economic efficiency among small-scale beekeepers in Tabora and Katavi regions, Tanzania: A stochastic profit frontier approach. Dev. Stud. Res. 2017, 4, 1-8. [CrossRef]

4. Ricketts, K.; Shackleton, C.M. Integrating livelihoods and forest conservation through beekeeping in northern KwaZulu-Natal. Dev. S. Afr. 2020, 37, 661-677. [CrossRef]

5. Breeze, T.D.; Gallai, N.; Garibaldi, L.A.; Li, X.S. Economic Measures of Pollination Services: Shortcomings and Future Directions. Trends Ecol. Evol. 2016, 31, 927-939. [CrossRef] [PubMed]

6. Garibaldi, L.A.; Carvalheiro, L.G.; Vaissière, B.E.; Gemmill-Herren, B.; Hipólito, J.; Freitas, B.M.; Ngo, H.T.; Azzu, N.; Sáez, A.; Åström, J.; et al. Mutually beneficial pollinator diversity and crop yield outcomes in small and large farms. Science 2016, 351, 388-391. [CrossRef]

7. Kasina, M.; Kraemer, M.; Martius, C.; Wittmann, D. Diversity and activity density of bees visiting crop flowers in Kakamega, Western Kenya. J. Apic. Res. Bee World 2009, 48, 134-139. [CrossRef] 
8. Warui, M.; Gikungu, M.; Bosselmann, A.; Hansted, L. Pollination of Acacia woodlands and honey production by honey bees in Kitui, Kenya. Future Food J. Food Agric. Soc. 2018, 6, 40-50.

9. Kasina, J.M.; Mburu, J.; Kraemer, M.; Holm-Mueller, K. Economic Benefit of Crop Pollination by Bees: A Case of Kakamega Small-Holder Farming in Western Kenya. J. Econ. Entomol. 2009, 102, 467-473. [CrossRef]

10. Awino, O.I.; Skilton, R.; Muya, S.; Kabochi, S.; Kutima, H.; Kasina, M. Varroa mites, viruses and bacteria incidences in Kenyan domesticated honeybee colonies. East Afr. Agric. For. J. 2016, 8325. [CrossRef]

11. Muli, E.; Patch, H.; Frazier, M.; Frazier, J.; Torto, B.; Baumgarten, T.; Kilonzo, J.; Kimani, J.N.; Mumoki, F.; Masiga, D.; et al. Evaluation of the distribution and impacts of parasites, pathogens, and pesticides on honey bee (Apis mellifera) populations in east Africa. PLoS ONE 2014, 9. [CrossRef]

12. Moran, N.A.; Tran, P.; Gerardo, N.M. Symbiosis and insect diversification: An ancient symbiont of sap-feeding insects from the bacterial phylum Bacteroidetes. Appl. Environ. Microbiol. 2005, 71, 8802-8810. [CrossRef] [PubMed]

13. Teixeira, L.; Ferreira, Á.; Ashburner, M. The bacterial symbiont Wolbachia induces resistance to RNA viral infections in Drosophila melanogaster. PLoS Biol. 2008, 6, e1000002. [CrossRef] [PubMed]

14. Hedges, L.M.; Brownlie, J.C.; O'Neill, S.L.; Johnson, K.N. Wolbachia and virus protection in insects. Science 2008, 322, 702. [CrossRef] [PubMed]

15. Werren, J.H.; Baldo, L.; Clark, M.E. Wolbachia: Master manipulators of invertebrate biology. Nat. Rev. Microbiol. 2008, 6, 741-751. [CrossRef]

16. Harumoto, T.; Lemaitre, B. Male-killing toxin in a bacterial symbiont of Drosophila. Nature 2018, 557, $252-255$. [CrossRef] [PubMed]

17. Dillon, R.J.; Vennard, C.T.; Charnley, A.K. Exploitation of gut bacteria in the locust. Nature 2000. [CrossRef]

18. Wada-Katsumata, A.; Zurek, L.; Nalyanya, G.; Roelofs, W.L.; Zhang, A.; Schal, C. Gut bacteria mediate aggregation in the German cockroach. Proc. Natl. Acad. Sci. USA 2015, 112, 201504031. [CrossRef]

19. Vernier, C.L.; Chin, I.M.; Adu-Oppong, B.; Krupp, J.J.; Levine, J.D.; Dantas, G.; Ben-Shahar, Y. The gut microbiome defines social group membership in honey bee colonies. Sci. Adv. 2020, 6, 1-10. [CrossRef] [PubMed]

20. Evans, J.D.; Armstrong, T.-N. Antagonistic interactions between honey bee bacterial symbionts and implications for disease. BMC Ecol. 2006, 6, 4. [CrossRef] [PubMed]

21. Jeyaprakash, A.; Hoy, M.A.; Allsopp, M.H. Bacterial diversity in worker adults of Apis mellifera capensis and Apis mellifera scutellata (Insecta: Hymenoptera) assessed using 16S rRNA sequences. J. Invertebr. Pathol. 2003, 84, 96-103. [CrossRef] [PubMed]

22. Kešnerová, L.; Mars, R.A.T.; Ellegaard, K.M.; Troilo, M.; Sauer, U.; Engel, P. Disentangling metabolic functions of bacteria in the honey bee gut. PLoS Biol. 2017, 15, e2003467. [CrossRef] [PubMed]

23. Raymann, K.; Moran, N.A. The role of the gut microbiome in health and disease of adult honey bee workers. Curr. Opin. Insect Sci. 2018, 26, 97-104. [CrossRef]

24. Schwarz, R.S.; Moran, N.A.; Evans, J.D. Early gut colonizers shape parasite susceptibility and microbiota composition in honey bee workers. Proc. Natl. Acad. Sci. USA 2016, 113, 9345-9350. [CrossRef]

25. Zheng, H.; Nishida, A.; Kwong, W.K.; Koch, H.; Engel, P.; Steele, M.I.; Moran, N.A. Metabolism of Toxic Sugars by Strains of the Bee Gut Symbiont Gilliamella apicola. MBio 2016, 7. [CrossRef] [PubMed]

26. Bonilla-Rosso, G.; Engel, P. Functional roles and metabolic niches in the honey bee gut microbiota. Curr. Opin. Microbiol. 2018, 43, 69-76. [CrossRef]

27. Kwong, W.K.; Medina, L.A.; Koch, H.; Sing, K.-W.; Jia, E.; Soh, Y.; Ascher, J.S.; Jaffé, R.; Moran, N.A. Dynamic microbiome evolution in social bees. Sci. Adv. 2017. [CrossRef]

28. Koch, H.; Abrol, D.P.; Li, J.; Schmid-Hempel, P. Diversity and evolutionary patterns of bacterial gut associates of corbiculate bees. Mol. Ecol. 2013, 22, 2028-2044. [CrossRef]

29. Martinson, V.G.; Danforth, B.N.; Minckley, R.L.; Rueppell, O.; Tingek, S.; Moran, N.A. A simple and distinctive microbiota associated with honey bees and bumble bees. Mol. Ecol. 2011, 20, 619-628. [CrossRef]

30. Kwong, W.K.; Moran, N.A. Cultivation and characterization of the gut symbionts of honey bees and bumble bees: Description of Snodgrassella alvi gen. nov., sp. nov., a member of the family Neisseriaceae of the betaproteobacteria, and Gilliamella apicola gen. nov., sp. nov., a memb. Int. J. Syst. Evol. Microbiol. 2013, 63, 2008-2018. [CrossRef]

31. Kwong, W.K.; Engel, P.; Koch, H.; Moran, N.A. Genomics and host specialization of honey bee and bumble bee gut symbionts. Proc. Natl. Acad. Sci. USA 2014, 111, 11509-11514. [CrossRef] [PubMed] 
32. Engel, P.; Martinson, V.G.; Moran, N.A. Functional diversity within the simple gut microbiota of the honey bee. Proc. Natl. Acad. Sci. USA 2012. [CrossRef]

33. Zheng, H.; Perreau, J.; Elijah Powell, J.; Han, B.; Zhang, Z.; Kwong, W.K.; Tringe, S.G.; Moran, N.A. Division of labor in honey bee gut microbiota for plant polysaccharide digestion. Proc. Natl. Acad. Sci. USA 2019, 116, 25909-25916. [CrossRef]

34. Kwong, W.K.; Moran, N.A. Gut microbial communities of social bees. Nat. Rev. Microbiol. 2016, 14, $374-384$. [CrossRef] [PubMed]

35. Powell, J.E.; Martinson, V.G.; Urban-Mead, K.; Moran, N.A. Routes of acquisition of the gut microbiota of the honey bee Apis mellifera. Appl. Environ. Microbiol. 2014, 80, 7378-7387. [CrossRef]

36. Zheng, J.; Wittouck, S.; Salvetti, E.; Franz, C.M.A.P.; Harris, H.M.B.; Mattarelli, P.; O'toole, P.W.; Pot, B.; Vandamme, P.; Walter, J.; et al. A taxonomic note on the genus Lactobacillus: Description of 23 novel genera, emended description of the genus Lactobacillus beijerinck 1901, and union of Lactobacillaceae and Leuconostocaceae. Int. J. Syst. Evol. Microbiol. 2020, 70, 2782-2858. [CrossRef]

37. Ellegaard, K.M.; Tamarit, D.; Javelind, E.; Olofsson, T.C.; Andersson, S.G.E.; Vásquez, A. Extensive intra-phylotype diversity in lactobacilli and bifidobacteria from the honeybee gut. BMC Genom. 2015, 16, 284. [CrossRef]

38. Moran, N.A.; Hansen, A.K.; Powell, J.E.; Sabree, Z.L. Distinctive gut microbiota of honey bees assessed using deep sampling from individual worker bees. PLoS ONE 2012, 7, e36393. [CrossRef]

39. Olofsson, T.C.; Vásquez, A. Detection and identification of a novel lactic acid bacterial flora within the honey stomach of the honeybee Apis mellifera. Curr. Microbiol. 2008, 57, 356-363. [CrossRef]

40. Vásquez, A.; Forsgren, E.; Fries, I.; Paxton, R.J.; Flaberg, E.; Szekely, L.; Olofsson, T.C. Symbionts as Major Modulators of Insect Health: Lactic Acid Bacteria and Honeybees. PLoS ONE 2012, 7. [CrossRef]

41. Audisio, M.C. Gram-Positive Bacteria with Probiotic Potential for the Apis mellifera L. Honey Bee: The Experience in the Northwest of Argentina. Probiotics Antimicrob. Proteins 2017, 9, 22-31. [CrossRef]

42. Evans, J.D.; Lopez, D.L. Bacterial probiotics induce an immune response in the honey bee (Hymenoptera: Apidae). J. Econ. Entomol. 2004, 97, 752-756. [CrossRef]

43. Forsgren, E.; Olofsson, T.C.; Vásquez, A.; Fries, I. Novel lactic acid bacteria inhibiting Paenibacillus larvae in honey bee larvae. Apidologie 2010, 41, 99-108. [CrossRef]

44. Anderson, K.E.; Sheehan, T.H.; Mott, B.M.; Maes, P.; Snyder, L.; Schwan, M.R.; Walton, A.; Jones, B.M.; Corby-Harris, V. Microbial ecology of the hive and pollination landscape: Bacterial associates from floral nectar, the alimentary tract and stored food of honey bees (Apis mellifera). PLoS ONE 2013, 8. [CrossRef]

45. Engel, P.; Bartlett, K.D.; Moran, A. The Bacterium Frischella perrara Causes Scab Formation in the Gut of its Honeybee Host. Mbio 2015, 6, 1-8. [CrossRef] [PubMed]

46. Emery, O.; Schmidt, K.; Engel, P. Immune system stimulation by the gut symbiont Frischella perrara in the honey bee (Apis mellifera). Mol. Ecol. 2017. [CrossRef]

47. Kešnerová, L.; Moritz, R.; Engel, P. Bartonella apis sp. nov., a honey bee gut symbiont of the class Alphaproteobacteria. Int. J. Syst. Evol. Microbiol. 2016, 66, 414-421. [CrossRef]

48. Siozios, S.; Moran, J.; Chege, M.; Hurst, G.D.D.; Paredes, J.C. Complete Reference Genome Assembly for Commensalibacter sp. Strain AMU001, an Acetic Acid Bacterium Isolated from the Gut of Honey Bees. Microbiol. Resour. Announc. 2019, 8,1-2. [CrossRef]

49. Kwong, W.K.; Moran, N.A. Apibacter adventoris gen. nov., sp. nov., a member of the phylum Bacteroidetes isolated from honey bees. Int. J. Syst. Evol. Microbiol. 2016, 66, 1323-1329. [CrossRef]

50. Kwong, W.K.; Steele, M.I.; Moran, N.A. Genome Sequences of Apibacter spp., Gut Symbionts of Asian Honey Bees. Genome Biol. Evol. 2018, 10, 1174-1179. [CrossRef]

51. Praet, J.; Aerts, M.; de Brandt, E.; Meeus, I.; Smagghe, G.; Vandamme, P. Apibacter mensalis sp. Nov.: A rare member of the bumblebee gut microbiota. Int. J. Syst. Evol. Microbiol. 2016, 66, 1645-1651. [CrossRef]

52. Mockler, B.K.; Kwong, W.K.; Moran, N.A.; Koch, H. Microbiome Structure Influences Infection by the Parasite Crithidia bombi in Bumble Bees. Appl. Environ. Microbiol. 2018, 84, 1-11. [CrossRef]

53. Ellegaard, K.M.; Engel, P. Genomic diversity landscape of the honey bee gut microbiota. Nat. Commun. 2019, 10, 446. [CrossRef]

54. Engel, P.; Stepanauskas, R.; Moran, N.A. Hidden Diversity in Honey Bee Gut Symbionts Detected by Single-Cell Genomics. PLoS Genet. 2014, 10. [CrossRef] [PubMed] 
55. Bleau, N.; Bouslama, S.; Giovenazzo, P. Dynamics of the Honeybee (Apis mellifera) Gut Microbiota Throughout the Overwintering Period in Canada. Microorganisms 2020, 8, 1146. [CrossRef] [PubMed]

56. Bosmans, L.; Pozo, M.I.; Verreth, C.; Crauwels, S.; Wäckers, F.; Jacquemyn, H.; Lievens, B. Hibernation leads to altered gut communities in Bumblebee queens (Bombus terrestris). Insects 2018, 9, 188. [CrossRef]

57. Brosi, B.J.; Daily, G.C.; Shih, T.M.; Oviedo, F.; Durán, G. The effects of forest fragmentation on bee communities in tropical countryside. J. Appl. Ecol. 2008, 45, 773-783. [CrossRef]

58. Jones, J.C.; Fruciano, C.; Hildebrand, F.; Al Toufalilia, H.; Balfour, N.J.; Bork, P.; Engel, P.; Ratnieks, F.L.W.; Hughes, W.O.H. Gut microbiota composition is associated with environmental landscape in honey bees. Ecol. Evol. 2018, 8. [CrossRef] [PubMed]

59. Kešnerová, L.; Emery, O.; Troilo, M.; Liberti, J.; Erkosar, B.; Engel, P. Gut microbiota structure differs between honeybees in winter and summer. ISME J. 2019, 14, 801-814. [CrossRef]

60. Mattila, H.R.; Rios, D.; Walker-Sperling, V.E.; Roeselers, G.; Newton, I.L.G. Characterization of the active microbiotas associated with honey bees reveals healthier and broader communities when colonies are genetically diverse. PLOS ONE 2012, 7. [CrossRef]

61. Rothman, J.A.; Carroll, M.J.; Meikle, W.G.; Anderson, K.E.; McFrederick, Q.S. Longitudinal Effects of Supplemental Forage on the Honey Bee (Apis mellifera) Microbiota and Inter- and Intra-Colony Variability. Microb. Ecol. 2018, 76, 814-824. [CrossRef]

62. D'Alvise, P.; Böhme, F.; Codrea, M.C.; Seitz, A.; Nahnsen, S.; Binzer, M.; Rosenkranz, P.; Hasselmann, M. The impact of winter feed type on intestinal microbiota and parasites in honey bees. Apidologie 2018, 49, $252-264$. [CrossRef]

63. Wang, H.; Liu, C.; Liu, Z.; Wang, Y.; Ma, L.; Xu, B. The different dietary sugars modulate the composition of the gut microbiota in honeybee during overwintering. BMC Microbiol. 2020, 20, 61. [CrossRef] [PubMed]

64. Wallberg, A.; Schöning, C.; Webster, M.T.; Hasselmann, M. Two extended haplotype blocks are associated with adaptation to high altitude habitats in East African honey bees. PLoS Genet. 2017. [CrossRef]

65. McMenamin, A.; Mumoki, F.; Frazier, M.; Kilonzo, J.; Mweu, B.; Baumgarten, T.; Patch, H.; Torto, B.; Masiga, D.; Tumlinson, J.; et al. The impact of hive type on the behavior and health of honey bee colonies (Apis mellifera) in Kenya. Apidologie 2017. [CrossRef]

66. Engel, P.; James, R.R.; Koga, R.; Kwong, W.K.; Mcfrederick, Q.S.; Moran, N.A. Standard methods for research on Apis mellifera gut symbionts. J. Apic. Res. 2013, 524, 1-24. [CrossRef]

67. Apprill, A.; Mcnally, S.; Parsons, R.; Weber, L. Minor revision to V4 region SSU rRNA 806R gene primer greatly increases detection of SAR11 bacterioplankton. Aquat. Microb. Ecol. 2015, 75, 129-137. [CrossRef]

68. Parada, A.E.; Needham, D.M.; Fuhrman, J.A. Every base matters: Assessing small subunit rRNA primers for marine microbiomes with mock communities, time series and global field samples. Environ. Microbiol. 2016, 18, 1403-1414. [CrossRef]

69. Callahan, B.J.; McMurdie, P.J.; Rosen, M.J.; Han, A.W.; Johnson, A.J.A.; Holmes, S.P. DADA2: High-resolution sample inference from Illumina amplicon data. Nat. Methods 2016, 13, 581-583. [CrossRef]

70. Bokulich, N.A.; Subramanian, S.; Faith, J.J.; Gevers, D.; Gordon, J.I.; Knight, R.; Mills, D.A.; Caporaso, J.G. Quality-filtering vastly improves diversity estimates from Illumina amplicon sequencing. Nat. Methods 2013, 10, 57-59. [CrossRef]

71. Camacho, C.; Coulouris, G.; Avagyan, V.; Ma, N.; Papadopoulos, J.; Bealer, K.; Madden, T.L. BLAST plus: Architecture and applications. BMC Bioinform. 2009, 10, 1. [CrossRef]

72. Lozupone, C.; Lladser, M.E.; Knights, D.; Stombaugh, J.; Knight, R. UniFrac: An effective distance metric for microbial community comparison. ISME J. 2011, 5, 169-172. [CrossRef]

73. Sabree, Z.L.; Hansen, A.K.; Moran, N.A. Independent studies using deep sequencing resolve the same set of core bacterial species dominating gut communities of honey bees. PLoS ONE 2012, 7. [CrossRef]

74. Ma, W.H.; Zheng, X.; Li, L.; Shen, J.; Li, W.; Gao, Y. Changes in the gut microbiota of honey bees associated with jujube flower disease. Ecotoxicol. Environ. Saf. 2020, 198, 110616. [CrossRef] [PubMed]

75. Ahn, J.-H.; Hong, I.-P.; Bok, J.-I.; Kim, B.-Y.; Song, J.; Weon, H.-Y. Pyrosequencing analysis of the bacterial communities in the guts of honey bees Apis cerana and Apis mellifera in Korea. J. Microbiol. 2012, 50, 735-745. [CrossRef]

76. Khan, K.A.; Ansari, M.J.; Al-Ghamdi, A.; Nuru, A.; Harakeh, S.; Iqbal, J. Investigation of gut microbial communities associated with indigenous honey bee (Apis mellifera jemenitica) from two different eco-regions of Saudi Arabia. Saudi J. Biol. Sci. 2017, 24, 1061-1068. [CrossRef] 
77. Sepulveda, J.; Moeller, A.H. The Effects of Temperature on Animal Gut Microbiomes. Front. Microbiol. 2020, 11, 1-9. [CrossRef]

78. Ludvigsen, J.; Rangberg, A.; Avershina, E.; Sekelja, M.; Kreibich, C.; Amdam, G.; Rudi, K. Shifts in the Midgut/Pyloric Microbiota Composition within a Honey Bee Apiary throughout a Season. Microbes Environ. 2015, 30, 235-244. [CrossRef]

79. Motta, E.V.S.; Raymann, K.; Moran, N.A. Glyphosate perturbs the gut microbiota of honey bees. Proc. Natl. Acad. Sci. USA 2018, 115, 10305-10310. [CrossRef]

80. Rouzé, R.; Moné, A.; Delbac, F.; Belzunces, L.; Blot, N. The honeybee gut microbiota is altered after chronic exposure to different families of insecticides and infection by Nosema ceranae. Microbes Environ. 2019, 34, 226-233. [CrossRef]

81. Maes, P.W.; Rodrigues, P.A.P.; Oliver, R.; Mott, B.M.; Anderson, K.E. Diet-related gut bacterial dysbiosis correlates with impaired development, increased mortality and Nosema disease in the honeybee (Apis mellifera). Mol. Ecol. 2016, 25, 5439-5450. [CrossRef]

82. Kakumanu, M.L.; Reeves, A.M.; Anderson, T.D.; Rodrigues, R.R.; Williams, M.A. Honey bee gut microbiome is altered by in-hive pesticide exposures. Front. Microbiol. 2016, 7, 1-11. [CrossRef]

Publisher's Note: MDPI stays neutral with regard to jurisdictional claims in published maps and institutional affiliations.

(C) 2020 by the authors. Licensee MDPI, Basel, Switzerland. This article is an open access article distributed under the terms and conditions of the Creative Commons Attribution (CC BY) license (http://creativecommons.org/licenses/by/4.0/). 